\title{
VIRTUAL INDEPENDENCE: TEEN SOCIAL MEDIA USE DURING THE SUMMER OF QUARANTINE
}

\author{
Vanessa P. Dennen, Stacey A. Rutledge, Lauren M. Bagdy, Stephen Bunn, Daeun Jung, \\ Casey Cargill, Catherine Cosgrove, Amber Hedquist and Shannon McWaters \\ Florida State University \\ Tallahassee, FL USA
}

\begin{abstract}
During Summer 2020, the COVID-19 pandemic limited people's contact with others outside of their households. Teenagers experienced a great deal of disruption to their lives and found themselves reliant on their phones and social media to occupy their time and maintain peer connections. In this study, we examine the activities of 43 teens in the United States. Teens were interviewed twice and kept week-long video diaries documenting their daily online and offline activities. Findings show that social media activities were critical for maintaining friendships and provided a sense of virtual independence during quarantine. Teens also pursued independent informal learning activities via social media. However, themes of shame also arose, with teens internalizing negative messages from parents and media about social media use.
\end{abstract}

\section{KEYWORDS}

COVID-19, Informal Learning, Social Media, Teenagers

\section{INTRODUCTION}

Teens' social media use is a complex activity that is often poorly understood by the adults in their lives. Social media accounts, nestled into apps on smartphones, provide teens with the ability to explore networked worlds privately while sitting in the same rooms as parents or teachers. Adults may dismiss teen online behavior as a waste of time or distraction, or they may try to surveil and scrutinize it as a measure of control over teen behavior (Dennen et al., 2019; Rutledge et al., 2019). Heavy teen social media use can be associated with poor mental health outcomes (Woods \& Scott, 2016), and also with fear of missing out (FOMO) (Barry et al., 2017). In this study, we look at how teens used social media platforms and their personal networks to foster virtual independence and satisfy a variety of personal needs. The study is situated during the Summer of 2020, when the COVID-19 pandemic slowed or curtailed most in-person social, educational, and work activities. This time frame offers a unique perspective on teen online life because it represents a period of increased reliance on online interactions for most teens (Dennen et al., 2021) and decreased reasons to experience FOMO.

\section{RESEARCH QUESTIONS}

The purpose of this study was to examine teens' online activities during the COVID-19 pandemic to see how social media helped or hindered their independence during this time. The study was conducted during summer, when school was out of session and great uncertainty loomed about the school year ahead. This study was guided by the following research questions:

1. How did teens use social media and networked technologies during the Summer of 2020?

2. How did teens use social media and networked technologies to support virtual independence and interests?

3. How did age and other factors inhibit or encourage virtual independence? 
We use the term social media and networked technologies (SMNT) in this study to be inclusive of the broad array of tools, platforms, and communication channels frequented by teens in this study. In other words, we were just as interested in their networked gaming interactions as we were in their Snapchat streaks.

\section{METHOD}

The participants in this study are 43 teenagers, aged 13 through 18, recruited from a midsize city in the United States. Participants were recruited via a survey. In selecting the sample, we attempted to distribute participants across age groups and include representation across zip codes and schools to ensure socioeconomic diversity. We also sought to balance gender and mirror the city's racial demographics to the extent possible. There were 25 female and 18 male participants. Table 1 provides an overview of the sample by age, race, and grade level. The study was approved by the Florida State University Human Subjects Committee. All participants provided consent or assent, and parents provided consent, as appropriate by age.

Table 1. Overview of participants

\begin{tabular}{cccccc}
\hline Age & $N$ & Grade & $N$ & Race & $N$ \\
\hline 13 & 7 & 7 & 5 & Asian & 2 \\
14 & 4 & 8 & 5 & Black & 13 \\
15 & 8 & 9 & 10 & Latinx & 1 \\
16 & 10 & 10 & 6 & Mixed Race & 3 \\
17 & 10 & 11 & 11 & White & 24 \\
\hline 18 & 4 & 12 & 6 & & 43 \\
\hline TOTAL & 43 & & 43 & & \\
\hline
\end{tabular}

Data collection included interviews and solicited diaries, which are helpful for capturing information about daily activities as well as reflective commentary about those activities (Bartlett \& Milligan, 2015). Each participant was interviewed twice, with 8-10 days between the interviews. Interviews were conducted by videoconference and lasted between 30 minutes and an hour. Between the two interviews, participants were asked to submit a diary record of their activities and their experiences using social media that day. The diary consisted of two parts: a form to systematically document social media use, activities, and happiness level each day, and a 3-5 minute video. Participants recorded diary entries for 5-7 days between interviews and were offered a gift card incentive for their participation. All interviews and video recordings were transcribed. Analysis involved thematic coding using inductive and deductive coding approaches. The deductive codes were derived from previous research (Dennen et al., 2020; Rutledge et al., 2019), while the inductive codes were derived from the interview and video recording data. Data analysis on the larger project is ongoing, and this paper reflects initial findings.

\section{FINDINGS}

\subsection{SMNT Use During Summer 2020}

Not surprisingly, most teens in this study described SMNT as their connection to the outside world during Summer 2020. Although their city was no longer under a stay-at-home order during the study, many teens were at home with parents every day, with nowhere to go. SMNT became a means of passing time, which manifested through passive activities such as streaming media and active ones such as interacting with close friends. A 16-year-old girl described this change in terms of her Snapchat use: 
Before quarantine I guess I used to send streaks. Like I had an 800-day streak with somebody who I didn't even necessarily talk to that much. We just sent streaks back and forth every day, and then that ended and I don't even - like I don't even have a streak with my boyfriend anymore. Like I just don't - I just don't really care. I mean, I'll look at people's stories, and I guess like I'll post something on like my private story every once in a while, but I mean, I don't really send streaks anymore.

Similarly, a 15-year-old boy shared how his choices about SMNT use reflect the desire to connect to specific people. He opted to not use Facebook because, "there were no people that I actually like knew on there. There was just like - I mean, there were people I knew, but not people that I would like - that I want to see their posts really." He went on to explain how his SMNT experience during Summer 2020 was focused on interacting with "friends that I have in real life. There was somebody I met online that I played [a networked game] with once, but after that I never talked to them again. And then there are some friends that I've made through other friends online, but they also live in [hometown], as far as I'm aware."

Although social media connected teens to friends, it was not necessarily a panacea. A 17-year-old boy shared, "When you don't have anything else to do and you sit at your house and you just pretty much are on it all day it can like really affect your happiness." Toward late summer 2020 this boy got a job and felt happier to be leaving the house. This teen and others expressed that social media alone could not satisfy their needs for human connection, but rather functioned as a temporary proxy during a difficult situation.

\subsection{SMNT, Virtual Independence, and Interests}

The teens relied heavily on their smartphones and computers to connect to their friends and entertain themselves during Summer 2020. However, the role of SMNT in fostering virtual independence was broader than just providing private spaces for social interaction, although that form of virtual independence is developmentally appropriate and its importance should not be underscored. SMNT enabled independent explorations of hobbies, entrepreneurship, identity, and values, as can be seen in these examples:

- Hobbies: A teen interested in makeup design occupied herself by accepting makeup "challenges" from her network that she would then recreate and share.

- Entrepreneurship: Three teens (unconnected) started their own businesses and marketed their products over social media, creating their own revenue streams.

- Identity: A transgender teen used SMNT to be his true self among friends, whereas with his family he was still maintaining the identity (e.g., name and gender) given to him at birth.

- Values: A teen whose mother would not allow her to attend local BLM protests learned about them via SMNT and made the choice to participate online.

Of these activities, only entrepreneurship involved parents. Parents were needed to set up bank accounts and procure supplies (e.g., parents controlled the household Amazon.com accounts or planned shopping trips). Otherwise, these activities were teen-initiated and in some instances done without any parent awareness.

\subsection{Age and Other Mitigating Factors}

In a time when physical distancing and isolation was encouraged, teens used their phones to maintain independent connections with friends and affinity spaces. Teens might be at home for days under the direct or indirect supervision of parents, but they still could have private conversations with close friends and congregate in adult-free spaces. Network size affected the types of activities that teens engaged in. Those who had smaller local friend networks pre-pandemic had fewer local network connections to maintain during the pandemic and were less likely to feel the social void created by staying at home.

Older teens expressed a greater sense of independence than younger teens both online and in the physical realm. Older teens reported that amid the pandemic they were still able to see friends, although they were doing so in smaller groups or 'pods.' Additionally, they would go to stores or restaurants to pick up items for the family. A common theme was transportation. Teens who were old enough to drive went out more frequently. A 14-year-old girl shared, "My mom definitely keeps me in the house. If it was my way I'd be out everywhere with my mask, and not - I'll take all the precautions, don't get me wrong, but I cannot be in this 
house." Because she could no longer go to the mall and cheer practice with friends, she spent time Facetiming and texting them and watching videos on TikTok.

Younger teens tended to have more constraints on their social media access and smartphones imposed by parents, although some parents of younger teens relented on prior rules considering the pandemic. For example, a 14-year-old boy said, "some of my friends, since they didn't have social media before, I think their parents let them get it during COVID. These friends like. Say, they didn't have a phone but they had a laptop or something." This connection between age and independence was observed in the data collection process, too. In most instances, we contacted teens directly to schedule interviews and provide reminders, but parents were intermediary contacts for some younger teens. We observed parenting differences by age in a pair of siblings. The older teen (age 16) appeared to have great freedom, going out with her friends and recording her video diaries in a number of locations where she was either alone or had off-camera friends nearby. In contrast, the younger sibling (age 14) always had parents in her vicinity when participating in interviews or video diaries.

Despite the positive independent activities that teens shared and the unusual circumstances imposed by the pandemic, an interesting emotion emerged: shame. Teens expressed anxiety that they were spending too much time online and were dismissive of the value entertainment-focused activities. For example, a 13-year-old girl declared herself "ashamed" of spending two hours watching TikTok videos one day, and later said she followed too many people. Another teen shared how she monitored her online time so she would know when it was too much. Upon probing, these teens had internalized and were repeating the words and judgments of adults who shamed them. In practice, they thought they should feel bad but were unlikely to change their behaviors. Adults not only modeled the shaming discourse, but also acted to prevent the shameful behavior. One 13-year-old participant lost phone privileges during the study period for spending too much time online. This punitive action demonstrates how critical phone access is for teens and how phones survey as a form of currency for achieving virtual independence.

\section{CONCLUSION}

The independence themes seen in this study echo other studies of teen online life. In a survey conducted during Summer 2020, a sample of 4762 teens reported using social media to connect with friends and entertain themselves, but a decrease in posting about themselves (Dennen et al., 2021). Other studies similarly noted an increase in screen time (Campbell et al., 2021) and identified friendship maintenance as an important way for teens to manage stress (Ellis et al., 2020). However, in contrast, Ellis et al. (2020) also found connections with depression and loneliness. The teens we spoke with missed seeing friends, but overall reported that they were happy. They were not conflicted about friendship maintenance over social media. The difference in findings may reflect the passing of time. Whereas Ellis et al. (2020) collected their data in April, when COVID-19 was a relatively new phenomenon and people were under stay-at-home orders. Another study conducted at that time found that teens were also driving less than usual, and primarily for employment (Stavrinos et al., 2020). In contrast, our data was collected in July and August, when people were used to taking COVID-related precautions, were venturing outside in the summer weather, and were more likely to gather in small, in-person pods.

In terms of independent online activities, our findings show that teens' online worlds extend beyond the social and entertainment functions most often ascribed to their social media use. Our study shows that students were able to construct virtual independence through their social media usage, showing how social media can serve as a space for developmentally appropriate differentiation from adults. Other studies have shed light on the complexity of teens' online activities. boyd (2014) discussed how teens engage in identity exploration online and civic engagement is another theme found in studies of teens online (Way \& Malvini Redden, 2017). Additionally, social media activities integrate an element of informal learning via SMNT, whether intrapersonal, interpersonal, or content-focused. These active forms of social media use have been associated with positive wellbeing outcomes for teens (Thorisdottir et al., 2019) and enable a sense of virtual independence.

Parents play a role in how teens construct their virtual independence. When parents control teens' access to devices and social media, their virtual independence is inhibited. Parent and media messages about the perils of social media activities and screen time lead teens to feel shameful about, diminish or hide their 
online activities, even when the activities represent important developmental milestones and lead to positive outcomes like learning. This finding is similar to another study that found that awareness of time spent online can trigger shame (Prasad \& Quinones, 2020). However, our findings suggest that teens are not just wasting time in their SMNT worlds, but instead blending entertainment with friendship maintenance and informal learning. The increased time spent online during the pandemic reflects having additional time to fill, and a shift in acceptable ways to connect with others.

These findings have implications for how adults interact with teens and monitor and discuss their SMNT use. Although the perils of online life cannot be denied and should not be understated, to ignore the important role that online worlds play in teens' lives for friendship maintenance and informal learning is short-sighted. Furthermore, shaming their activities is not productive. Teens navigate complex social media landscapes daily. They may not do so perfectly or without any negative moments, but they learn from their experiences, and their experiences managing their SMNT worlds during the pandemic shows that they can merge these pieces of virtual independence with their physical worlds.

\section{ACKNOWLEDGEMENT}

This study was funded by a COVID-19 Seed Grant from Florida State University.

\section{REFERENCES}

Barry, C. T., Sidoti, C. L., Briggs, S. M., Reiter, S. R., \& Lindsey, R. A. (2017). Adolescent social media use and mental health from adolescent and parent perspectives. Journal of Adolescence, 61, 1-11. https://doi.org/10.1016/j.adolescence.2017.08.005

Bartlett, R., \& Milligan, C. (2015). What is a diary method? Bloomsbury Academic. https://doi.org/10.5040/9781472572578

boyd, d. m. (2014). It's complicated: The social lives of networked teens. Yale University Press.

Campbell, K., Weingart, R., Ashta, J., Cronin, T., \& Gazmararian, J. (2021). COVID-19 knowledge and behavior change among high school students in semi-rural Georgia. Journal of School Health. https://doi.org/10.1111/josh.13029

Dennen, V. P., Rutledge, S. A., \& Bagdy, L. M. (2019). Social media use in high school settings: Rules, outcomes, and educational opportunities. In Proceedings of the 10th International Conference on Social Media and Society (pp. 205-213). ACM. https://doi.org/10.1145/3328529.3328561

Dennen, V. P., Rutledge, S. A., \& Bagdy, L. M. (2020). (Dis)connected: The role of social networking sites in the high school setting. American Journal of Education, 127(1), 107-136.

Dennen, V. P., Rutledge, S. A., Bagdy, L. M., Bunn, S., Jung, D., Cargill, C., Cosgrove, C., Hedquist, A., \& McWaters, S. (2021, April 8-12). Teenage social media use in the time of COVID-19: Resilience, connection, entertainment, and learning [Conference Poster]. American Educational Research Association, online. http://aera21aera.ipostersessions.com/Default.aspx?s=6C-5D-EC-AD-C6-F2-B8-14-3B-70-E6-3C-62-67-53-69

Ellis, W. E., Dumas, T. M., \& Forbes, L. M. (2020). Physically isolated but socially connected: Psychological adjustment and stress among adolescents during the initial COVID-19 crisis. Canadian Journal of Behavioural Science / Revue canadienne des sciences du comportement, 52(3), 177-187. https://doi.org/10.1037/cbs0000215

Prasad, A., \& Quinones, A. (2020). Digital overload warnings: The right amount of shame? International Conference on Human-Computer Interaction,

Rutledge, S. A., Dennen, V. P., Bagdy, L. M., Rowlett, J. T., \& Burnick, S. (2019). Exploring adolescent social media use in a high school: Tweeting teens in a bell schedule world. Teachers College Record Yearbook, 121(14).

Stavrinos, D., McManus, B., Mrug, S., He, H., Gresham, B., Albright, M. G., Svancara, A. M., Whittington, C., Underhill, A., \& White, D. M. (2020). Adolescent driving behavior before and during restrictions related to COVID-19. Accid Anal Prev, 144, 105686. https://doi.org/10.1016/j.aap.2020.105686

Thorisdottir, I. E., Sigurvinsdottir, R., Asgeirsdottir, B. B., Allegrante, J. P., \& Sigfusdottir, I. D. (2019). Active and passive social media use and symptoms of anxiety and depressed mood among Icelandic adolescents. Cyberpsychol Behav Soc Netw, 22(8), 535-542. https://doi.org/10.1089/cyber.2019.0079

Way, A. K., \& Malvini Redden, S. (2017). The study of youth online: A critical review and agenda. Review of Communication, 17(2), 119-136. https://doi.org/10.1080/15358593.2017.1293838

Woods, H. C., \& Scott, H. (2016). \#Sleepyteens: Social media use in adolescence is associated with poor sleep quality, anxiety, depression and low self-esteem. J Adolesc, 51, 41-49. https://doi.org/10.1016/j.adolescence.2016.05.008 